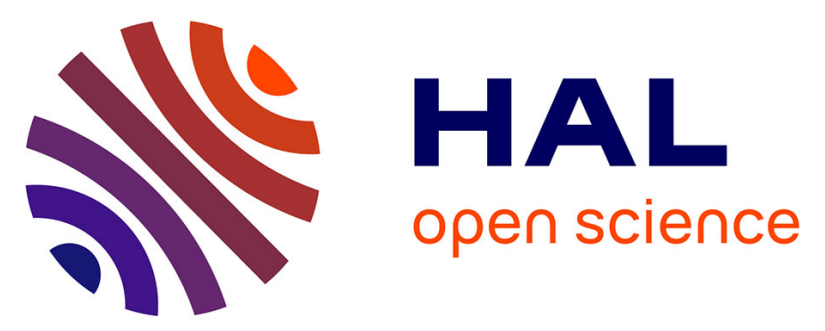

\title{
Assessing arsenic redox state evolution in solution and solid phase during As(III) sorption onto chemically-treated sewage sludge digestate biochars
}

Suchanya Wongrod, Stéphane Simon, Eric D. van Hullebusch, Piet N L Lens, Gilles Guibaud

\section{To cite this version:}

Suchanya Wongrod, Stéphane Simon, Eric D. van Hullebusch, Piet N L Lens, Gilles Guibaud. Assessing arsenic redox state evolution in solution and solid phase during As(III) sorption onto chemically-treated sewage sludge digestate biochars. Bioresource Technology, 2019, 275, pp.232-238. 10.1016/j.biortech.2018.12.056 . hal-02053007

\section{HAL Id: hal-02053007 https://hal.science/hal-02053007}

Submitted on 28 Feb 2019

HAL is a multi-disciplinary open access archive for the deposit and dissemination of scientific research documents, whether they are published or not. The documents may come from teaching and research institutions in France or abroad, or from public or private research centers.
L'archive ouverte pluridisciplinaire HAL, est destinée au dépôt et à la diffusion de documents scientifiques de niveau recherche, publiés ou non, émanant des établissements d'enseignement et de recherche français ou étrangers, des laboratoires publics ou privés. 


\section{Accepted Manuscript}

Assessing arsenic redox state evolution in solution and solid phase during As(III) sorption onto chemically-treated sewage sludge digestate biochars

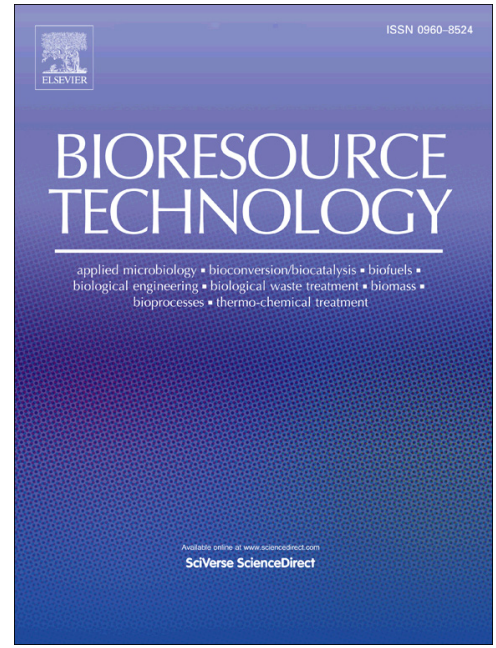

Suchanya Wongrod, Stéphane Simon, Eric D. van Hullebusch, Piet N.L. Lens, Gilles Guibaud

PII:

DOI:

Reference:

To appear in:

Received Date:

Revised Date:

Accepted Date:
S0960-8524(18)31717-6 https://doi.org/10.1016/j.biortech.2018.12.056

BITE 20813

Bioresource Technology

15 October 2018

10 December 2018

16 December 2018

Please cite this article as: Wongrod, S., Simon, S., van Hullebusch, E.D., Lens, P.N.L., Guibaud, G., Assessing arsenic redox state evolution in solution and solid phase during As(III) sorption onto chemically-treated sewage sludge digestate biochars, Bioresource Technology (2018), doi: https://doi.org/10.1016/j.biortech.2018.12.056

This is a PDF file of an unedited manuscript that has been accepted for publication. As a service to our customers we are providing this early version of the manuscript. The manuscript will undergo copyediting, typesetting, and review of the resulting proof before it is published in its final form. Please note that during the production process errors may be discovered which could affect the content, and all legal disclaimers that apply to the journal pertain. 
Assessing arsenic redox state evolution in solution and solid phase during As(III) sorption onto chemically-treated sewage sludge digestate biochars

Suchanya Wongrod ${ }^{\mathrm{a}, \mathrm{b}, \mathrm{c}}$, Stéphane Simon ${ }^{\mathrm{b},{ }^{*}, \text { Eric D. van Hullebusch }}{ }^{\mathrm{a}, \mathrm{c}, \mathrm{d}}$, Piet N.L. Lens ${ }^{\mathrm{c}}$, Gilles Guibaud ${ }^{\mathrm{b}}$

${ }^{a}$ Université Paris-Est, Laboratoire Géomatériaux et Environnement (EA 4508), UPEM, 77454, Marne-laVallée, France

${ }^{\mathrm{b}}$ Université de Limoges, PEIRENE, Équipe Développement d'indicateurs ou prévision de la qualité des eaux, URA IRSTEA, 123 avenue Albert Thomas, 87060 Limoges, France

${ }^{\mathrm{c}}$ IHE Delft Institute for Water Education, P.O. Box 3015, 2601 DA Delft, The Netherlands

${ }^{\mathrm{d}}$ Institut de Physique du Globe de Paris, Sorbonne Paris Cité, Université Paris Diderot, UMR 7154, CNRS, F75005 Paris, France

\begin{abstract}
This work aimed to determine arsenic redox state distribution during As(III) sorption onto chemically-modified biochars. A solid-liquid extraction protocol using phosphoric $(0.3 \mathrm{M})$ and ascorbic $(0.5 \mathrm{M})$ acids at $80^{\circ} \mathrm{C}$ for 20 min was established to ensure a quantitative recovery and stability of As(III) during the extraction. During sorption experiments, the redox conversions of As occurred and As(III) was either stable or partially oxidized in solution. The As distribution strongly varies depending on the biochar chemical treatment
\end{abstract}

\footnotetext{
${ }^{*}$ Corresponding author. Université de Limoges, PEIRENE, Équipe Développement d'indicateurs ou prévision de la qualité des eaux, URA IRSTEA, 123 avenue Albert Thomas, 87060 Limoges, France

Email: stephane.simon@unilim.fr
} 
performed as well as the selected washing procedures (batch versus column washings). As(III) oxidation was favored with the $\mathrm{KOH}$-modified biochar washed in batch mode. This oxidation was mostly induced by the biochar solid compounds rather than by soluble compounds released in solution. The As redox state distribution of As sorbed onto the biochars was successfully assessed using the extraction procedure. Arsenic was predominantly sorbed as As(III) (76-92\%) onto the biochars.

Keywords: Sewage sludge digestate biochar, As(III) removal, arsenic redox distribution, sorption

\section{Introduction}

Elevated concentrations of arsenic (As) in water bodies represent a global environmental and health issue because of its toxic features. The increasing threats of As contamination mainly originate from anthropogenic sources, particularly mining, industrial and agricultural activities (Vithanage et al., 2017). Arsenic toxicity in targeted organisms is strongly linked to its chemical speciation, especially its redox state. Indeed, organic forms of As such as monomethylarsonic acid (MMA) and dimethylarsinic acid (DMA) present intermediate toxicity, whereas inorganic As species, i.e. arsenite (As(III)) and arsenate $(\mathrm{As}(\mathrm{V}))$, are known as the most toxic ones (Hughes et al., 2011).

Regarding the acute toxicity of As, efforts have been made to efficiently remove As from polluted water streams by using several treatment techniques such as oxidation, 
coagulation-flocculation, ion exchange, phytoremediation, membrane separation and adsorption (Jadhav et al., 2015; Jain and Singh, 2012; Singh et al., 2015). Among these methods, sorption is well known as a cost effective approach to remediating metal(loid)s polluted water (Ahmad et al., 2014). Biochar is a charcoal obtained from pyrolysis of biowaste materials in an oxygen-limited environment (Novotny et al., 2015). Because of the low-cost and the great abundance of biowaste feedstocks (e.g. sewage sludge digestate obtained from wastewater treatment streams), biochars are considered as alternatively potential sorbents for metal(loid)s removal from water (Mohan et al., 2014). Most of the sewage sludge biochars were used to sorb cationic metals like lead $(\mathrm{Pb}(\mathrm{II}))$ and chromium (Cr(VI)) (Ifthikar et al., 2017; Lu et al., 2012; Zhang et al., 2013), and to a lesser extent to metalloids like arsenic (As) and antimony (Sb). Thus, the development of sewage sludge biochar with chemical modification to improve As sorption (Sizmur et al., 2017) as well as the investigation of As speciation is of great interest. To date, As redox species repartition during the adsorption process onto biochar, and the role of biochar on redox modifications of As are not known. Hence, it is worthwhile to investigate the redox transformation of As(III) during its sorption onto biochars, since As(III) is more toxic and weakly bound to solid material than As(V) (Manning et al., 2002). Therefore, the As(III) oxidation induced by biochars is an important reaction that can possibly decrease As toxicity in As polluted water bodies.

Arsenic speciation in solid-phase samples can be accessed via X-ray absorption near edge structure (XANES) spectroscopy (Niazi et al., 2018a, 2018b). However, the use of this technique is limited due to the very high operation cost and the accessibility to synchrotron 
facilities. Solid-liquid extraction followed by separation techniques, for instance liquid chromatography (LC) coupled to spectrometric detection techniques such as atomic fluorescence spectroscopy (AFS) or inductively coupled plasma mass spectrometry (ICPMS), could be an effective and more accessible technique to determine the As species sorbed onto the solid-phase samples.

The present study focused on the determination of the inorganic As redox distribution in raw sewage sludge digestate (SSD) biochar and the $\mathrm{H}_{2} \mathrm{O}_{2}$ and $\mathrm{KOH}$ modified biochars before and after As(III) sorption using an analytical approach based on a solid-liquid extraction. At present, no study has reported on the implementation of an extraction method to recover $\mathrm{As}(\mathrm{III})$ and $\mathrm{As}(\mathrm{V})$ from the solid-phase of biochar. An extraction method using phosphoric and ascorbic acids as extracting agents was thus investigated before studying the possibility of redox transformations of As(III) during sorption experiments onto the biochar. The main objectives of this work were to: (1) validate the extraction procedure for $\mathrm{As}(\mathrm{III})$ and $\mathrm{As}(\mathrm{V})$ speciation in the biochars; (2) investigate the sorption ability for As(III) by the raw and chemically-modified biochars; and (3) report on the redox conversions of arsenic during the sorption experiments.

\section{Material and methods}

\subsection{Biochar production and chemical modification}

Sewage sludge digestate (SSD) was collected from a wastewater treatment plant (WWTP) located in Limoges (France), after its dewatering and drying processes. Biochar was 
produced from the SSD sample under slow pyrolysis conditions (at $350{ }^{\circ} \mathrm{C}$ for $15 \mathrm{~min}$ ) (Wongrod et al., 2018a). The SSD biochar (100 g) was then modified with a $1 \mathrm{~L}$ of $10 \%$ $\mathrm{H}_{2} \mathrm{O}_{2}$ solution (modified from Xue et al., 2012) or with a $2.5 \mathrm{~L}$ of $2 \mathrm{M} \mathrm{KOH}$ solution (modified from Jin et al., 2014). For each biochar modification, the mixed biochar-solution was continuously stirred at room temperature for $2 \mathrm{~h}$.

Raw and modified biochars were further washed with ultrapure water (18.2 M $\Omega$, MilliQ Gradient A10, Millipore SAS 67120, Molsheim, France) in a batch system (triplicate in a row) followed by a continuous column washing (Wongrod et al., 2018a). These washing steps were performed to eliminate releasable organic compounds and inorganic ions (i.e. $\mathrm{PO}_{4}{ }^{3-}, \mathrm{HCO}_{3}{ }^{-}, \mathrm{CO}_{3}{ }^{2-}, \mathrm{Ca}^{2+}$ and $\mathrm{Mg}^{2+}$ ) from the prepared biochars, particularly after chemical modification. The $\mathrm{KOH}$ modified biochar was also submitted to only a triple batch washing (Huang et al., 2017; Regmi et al., 2012; Wongrod et al., 2018a; Wu et al., 2017) to study the influence of washing steps onto As sorption and redox transformations.

The raw, $\mathrm{H}_{2} \mathrm{O}_{2}$ and $\mathrm{KOH}$ modified SSD biochars are labeled as $\mathrm{BSS}, \mathrm{BH}_{2} \mathrm{O}_{2}$ and $\mathrm{BKOH}$, respectively. The $\mathrm{KOH}$ modified SSD biochar with only batch washing is denoted as $\mathrm{BKOH}^{\text {bat }}$

\subsection{Biochar characterization}

The $\mathrm{pH}$ of the biochar was measured using a pH-meter (LPH 330T, Tacussel, France) after stirring $1 \mathrm{~g}$ biochar in $20 \mathrm{~mL}$ deionized water for $5 \mathrm{~min}$ and allowed it to settle for $15 \mathrm{~min}$. The electrical conductivity (EC) of biochar was measured using a conductivity meter at 20 ${ }^{\circ} \mathrm{C}$ (CDM 210, Radiometer, Denmark). 
The Brunauer-Emmett-Teller surface area $\left(\mathrm{S}_{\mathrm{BET}}\right)$ of biochar was measured using $\mathrm{N}_{2}$ sorption at $77 \mathrm{~K}$ (3Flex, Micromeritics, USA) after pretreatment of biochar by drying at $105^{\circ} \mathrm{C}$ for $5 \mathrm{~h}$. The $\mathrm{pH}$ of point of zero charge $\left(\mathrm{pH}_{\mathrm{PZC}}\right)$ of the biochar was determined from the zeta potential at different $\mathrm{pH}$ ranges (Mahmood et al., 2011). The cation exchange capacity (CEC) of the biochar was determined by using a cobalt hexamine trichloride solution (99\% w/w, Sigma-Aldrich) (Aran et al., 2008).

\subsection{Sorption experiments}

A $13.33 \mathrm{mM}$ stock solution of arsenite (As(III)) was prepared from $\mathrm{AsNaO}_{2}(98 \% \mathrm{w} / \mathrm{w}$, Merck) and was diluted to $50 \mu \mathrm{M}$ prior to As(III) sorption and arsenic speciation (i.e. $\mathrm{As}(\mathrm{III})$ and $\mathrm{As}(\mathrm{V}))$ experiments. Biochar $(0.15 \mathrm{~g})$ was separately added to $37.5 \mathrm{~mL}$ of As(III) solution in a polyethylene tube to obtain an initial $146 \mu \mathrm{g}$ of As(III) in the solution. The initial $\mathrm{pH}$ was adjusted to $5.0( \pm 0.5)$ by adding $0.01 \mathrm{M} \mathrm{HNO}_{3}$ or $\mathrm{NaOH}$. The sorption experiments were performed in triplicate at $20( \pm 2)^{\circ} \mathrm{C}$ at $180 \mathrm{rpm}$ for $24 \mathrm{~h}$ using an orbital shaker (KS 501 digital, IKA ${ }^{\mathrm{TM}}$, USA).

The significant presence in solution of releasable dissolved compounds (RDC) from $\mathrm{BKOH}^{\text {bat }}$ (Wongrod et al., 2018a) could affect arsenic speciation. To determine whether the arsenic oxidation was mainly induced by the biochar itself or by these RDC, a control experiment was carried out. For this purpose, $1 \mathrm{~g} \mathrm{BKOH}^{\text {bat }}$ in $250 \mathrm{~mL}$ ultrapure water was stirred at $180 \mathrm{rpm}$ for $24 \mathrm{~h}$ at room temperature $\left(20^{\circ} \mathrm{C}\right)$. The resulting solution was filtered with a $0.2 \mu \mathrm{m}$ polyethersulfone (PES) membrane filter to remove the solid biochar. The 
resulting solution thus only contains the RDC. A control experiment was then performed by replacing the $\mathrm{BKOH}^{\text {bat }}$ by this solution of $\mathrm{RDC}$ during sorption kinetics experiments.

In all these experiments, samples were collected at 1, 3, 7, 16 and $24 \mathrm{~h}$. The total sampled volume was less than $5 \%$ of the initial volume to avoid any disturbance on the sorption equilibrium. Solutions were filtered through a $0.2 \mu \mathrm{m}$ PES syringe filter and stored in a dark cold room at $4{ }^{\circ} \mathrm{C}$ until analysis.

\subsection{Arsenic redox state distribution in biochars}

Total As and its redox state distribution in raw and chemically-modified biochars before and after As(III) sorption experiments were determined through solution analysis, extraction and acid digestion as described in the following subsections.

\subsubsection{Arsenic analysis in solution and deduction of sorbed arsenic.}

Total arsenic analysis was performed using graphite furnace atomic absorption spectrometry (GF-AAS) (240Z, Agilent Technologies, USA) at $\lambda 193.7 \mathrm{~nm}$. The standard calibrations of As were prepared in the ranges of $10-50 \mu \mathrm{g} \mathrm{L}^{-1}$. The detection limit was estimated from the mean of the blank and standard deviation, and the analyte solution was measured to produce a signal of at least 3 times higher signal than the noise level.

The arsenic redox distribution was assessed by liquid chromatography coupled to atomic fluorescence spectroscopy (LC-AFS) with hydride generation (HG) (PS Analytical Millennium Excalibur, PS Analytical, UK). The chromatographic separation was performed using a Hamilton PRP-X100 column with a phosphate buffer solution as the mobile phase 
at $\mathrm{pH} 6.9$ and at a flow rate of $1 \mathrm{~mL} \mathrm{~min}^{-1}$. The details of the experimental conditions for speciation analysis can be found in a previous study reported by Wan et al. (2014). To avoid any transformation between $\mathrm{As}(\mathrm{III})$ and $\mathrm{As}(\mathrm{V})$, arsenic speciation on both liquid and extracted solutions was performed within $5 \mathrm{~h}$ after sample recovery.

The amount of As sorbed onto the biochar was calculated from differences between initial and final concentrations of arsenic during sorption experiments. The sorbed As onto biochar can be calculated following Equation (1):

$$
Q_{\text {sol. }}=\left(C_{i}-C_{f}\right) \times V
$$

where $Q_{\text {sol. }}$ is the amount of arsenic sorbed onto biochar $(\mu \mathrm{g})$ (based on $0.15 \mathrm{~g}$ of biochar in this study), $C_{i}$ and $C_{f}$ are, respectively, initial and final equilibrium concentrations of arsenic in the solution, and $V$ is the total volume of the solution (L).

\subsubsection{Extraction of $A s(I I I)$ and As(V) from biochar}

Due to the lack of a soft extraction procedure for arsenic from biochar in the literature, this study designed one extraction method based on the extraction procedures described by Thomas et al. (1997), Montperrus et al. (2002) and Zhang et al. (2015). The extractant was prepared from $0.3 \mathrm{M}$ phosphoric acid $\left(\mathrm{H}_{3} \mathrm{PO}_{4}, 85 \% \mathrm{w} / \mathrm{w}\right.$, Carlo ERBA) with or without the addition of $0.5 \mathrm{M}$ ascorbic acid (99.5\% w/w, Fluka). Ascorbic acid was used to prevent the oxidation of As(III) in the solution during the extraction (Xu et al., 2015).

After the sorption experiments, $0.15 \mathrm{~g}$ of biochar was quickly rinsed 3 times with ultrapure water and transferred into a Teflon digestion tube with $25 \mathrm{~mL}$ of the extracting solution. 
The extraction was operated using microwave assistance (Multiwave GO, Anton Paar, France) by heating at $80^{\circ} \mathrm{C}$ for $20 \mathrm{~min}$. The resulting solution was then centrifuged (Multifuge X3 FR, Thermo Fisher Scientific) at $3400 \mathrm{rpm}$ for $20 \mathrm{~min}$. The supernatant was collected and filtered through a $0.2 \mu \mathrm{m}$ PES syringe filter and diluted to a constant volume of $50 \mathrm{~mL}$. Samples were analyzed for As speciation using LC-AFS as mentioned in section

\subsection{1.}

\subsubsection{Biochar acid digestion for total arsenic measurements}

After the sorption experiments, the biochar (about $0.15 \mathrm{~g}$ ) was rinsed with ultrapure water and transferred into a digestion tube (Teflon). Concentrated nitric acid $\left(\mathrm{HNO}_{3}, 69.5 \% \mathrm{w} / \mathrm{w}\right.$, Panreac ITW) $(6 \mathrm{~mL})$ was added to the digestion tube. Hydrogen peroxide $\left(\mathrm{H}_{2} \mathrm{O}_{2}, 30 \%\right.$ $w / w$, Carlo ERBA) $(6 \mathrm{~mL})$ was then slowly added into the digestion tube with a caution regarding its strong oxidizing property. The digestion tube was left overnight $(12 \mathrm{~h})$ to oxidize and digest organic matter in biochar prior to a microwave acid digestion (in order to avoid over-pressure due to the high initial release of $\mathrm{CO}_{2}$ ). Finally, $3 \mathrm{~mL}$ of concentrated hydrochloric acid $(\mathrm{HCl}, 37 \% \mathrm{w} / w, \mathrm{VWR})$ were added before starting the digestion that was operated at $180^{\circ} \mathrm{C}$ for $4 \mathrm{~h}$ ( 4 cycles) using a microwave digestion ( 1 cycle per $1 \mathrm{~h}$ ) to sufficiently digest all biochar particles. After digestion, the resulting solution was recovered and the dilution in a $50 \mathrm{~mL}$ volume was made with ultrapure water. It was filtered through a $0.2 \mu \mathrm{m}$ PES syringe filter before analysis. Total arsenic content was analyzed by GF-AAS as previously mentioned in section 2.4.1. Regarding the analysis of total arsenic in the biochars, the As content that is already present in each biochar (before sorption) was 
deduced from the sorbed As after the As(III) sorption experiments. This deduction was made to avoid errors in the experimental results.

\subsection{Statistical analysis}

The biochar characteristics and As(III) sorption experiments were carried out in triplicate. Results are reported as the mean value followed by standard deviation. Constants for sorption parameters were obtained by the non-linear regression using Statistica software (v6.1, StatSoft). Statistical analysis of the experimental data was performed by the t-test with two-tailed distribution at a statistical significance level of $p \leq 0.01$.

\section{Results and discussion}

\subsection{Characterization of raw and chemically-modified biochars}

The total As content in the raw and chemically-modified biochars is given in Table $\mathbf{1}$. Results show a significant $(p \leq 0.01)$ decrease of the As content after treating the raw biochar with $\mathrm{H}_{2} \mathrm{O}_{2}$ or $\mathrm{KOH}$ from $47( \pm 1) \mu \mathrm{g} \mathrm{g}^{-1}$ for BSS to $29( \pm 1)$ and $13( \pm 1) \mu \mathrm{g} \mathrm{g}^{-1}$, respectively, for $\mathrm{BH}_{2} \mathrm{O}_{2}$ and $\mathrm{BKOH}$. These reductions can be due to the ability of $\mathrm{KOH}$ to dissolve ash contents (Lin et al., 2012; Liou and Wu, 2009; Liu et al., 2012) and $\mathrm{H}_{2} \mathrm{O}_{2}$ to oxidize organic matter present in the solid phase of the biochars (Xue et al., 2012). As a result, the As bound to the biochar matrix could be chemically altered and thus the As contents were lower in the chemically-modified biochars compared to the raw biochar (Table 1). 
Considering $\mathrm{BKOH}$ and $\mathrm{BKOH}^{\text {bat }}$, an almost 2 times decrease of As, from $23( \pm 2) \mu \mathrm{g} \mathrm{g}^{-1}$ for $\mathrm{BKOH}^{\text {bat }}$ to $13( \pm 1) \mu \mathrm{g} \mathrm{g}^{-1}$ for $\mathrm{BKOH}$, was found after the subsequent continuous column washing.

The $\mathrm{pH}$ values of all biochar suspensions are also provided in Table 1. The $\mathrm{pH}$ of BSS (6.4 $\pm 0.1)$ increased to $8.4( \pm 0.1)$ and $10.1( \pm 0.1)$ for $\mathrm{BKOH}$ and $\mathrm{BKOH}^{\text {bat }}$, respectively, whereas $\mathrm{H}_{2} \mathrm{O}_{2}$ induced no significant change $(p \leq 0.01)$ on the $\mathrm{pH}$ suspension of biochar. The electrical conductivity (EC) of biochar suspensions remained in similar ranges from $4.0( \pm 0.1)$ to $4.1( \pm 0.3)$ and $6.2( \pm 0.5) \mu \mathrm{S} \mathrm{cm}^{-1}$ for $\mathrm{BSS}, \mathrm{BH}_{2} \mathrm{O}_{2}$ and $\mathrm{BKOH}$, respectively. However, a significantly higher EC value $\left(324 \pm 2 \mu \mathrm{S} \mathrm{cm}^{-1}\right)$ for $\mathrm{BKOH}^{\text {bat }}$ was found, compared to $\mathrm{BKOH}$ (Table 1). This highlights the ability of $\mathrm{BKOH}^{\text {bat }}$ to release a relatively high amount of dissolved ions as previously reported by Wongrod et al. (2018a).

The $\mathrm{pH}_{\mathrm{PZC}}$ and zeta potential (at $\mathrm{pH}$ 5) values of the raw and chemically-modified biochars are given in Table 1. Results showed similar $\mathrm{pH}_{\mathrm{PZC}}$ ranges (2.7-3.4) among the raw and modified biochars. Currently, there is still a lack of information regarding $\mathrm{pH}_{\mathrm{PZC}}$ of biochars reported in the literature. Nevertheless, these findings are consistent with previous studies from Qiu et al. (2009) who reported a $\mathrm{pH}_{\mathrm{PZC}}$ of 1.9 on straw biochar and Petrovic et al. (2016) with $\mathrm{pH} P \mathrm{PC}$ values of 4.5 and 6.0, respectively, on grape pomace biochar and its $\mathrm{KOH}$ modified biochar. Moreover, the negative zeta potential values of the biochars implied that all biochars carried net negative charges at $\mathrm{pH} 5$, particularly for the $\mathrm{BH}_{2} \mathrm{O}_{2}(-$ $16.5 \mathrm{mV})$ and $\mathrm{BKOH}^{\text {bat }}(-17.1 \mathrm{mV})$. These negatively charges may hinder the sorption ability for arsenic oxyanions at $\mathrm{pH} 5$. 
The BET surface area $\left(\mathrm{S}_{\mathrm{BET}}\right)$ of all biochars is reported in Table 1. The $\mathrm{S}_{\mathrm{BET}}$ was significantly improved by 7-20 times after $\mathrm{H}_{2} \mathrm{O}_{2}$ or $\mathrm{KOH}$ modification of the biochar compared to the non-treated biochar. In this case, the $\mathrm{S}_{\mathrm{BET}}$ increased from $0.4( \pm 0.1)$ (the raw biochar) to $5.7( \pm 0.1)$ and $7.9( \pm 0.1) \mathrm{m}^{2} \mathrm{~g}^{-1}$ for $\mathrm{BH}_{2} \mathrm{O}_{2}$ and $\mathrm{BKOH}$, respectively. This implies that $\mathrm{H}_{2} \mathrm{O}_{2}$ and $\mathrm{KOH}$ induced higher porosity on the modified biochars, thus As sorption can be enhanced for these biochars (Mohan et al., 2014). These $\mathrm{S}_{\mathrm{BET}}$ results are in agreement with those reported for sewage sludge biochars $\left(4.0-14.3 \mathrm{~m}^{2} \mathrm{~g}^{-1}\right)$ (Agrafioti et al., 2013; Yuan et al., 2015), but lower than biochar made from wood $\left(475 \mathrm{~m}^{2} \mathrm{~g}^{-1}\right)$ (Niazi et al., 2018b). Nevertheless, they remain very low compared to activated carbon which displays specific surface area beyond $1000 \mathrm{~m}^{2} \mathrm{~g}^{-1}$ in most cases (Gonzalez-Garcia, 2018) (e.g. 1215.0-1316.0 $\mathrm{m}^{2} \mathrm{~g}^{-1}$ for activated carbon prepared from coal) (Gong et al., 2015). The CEC values for all biochars are also given in Table 1. Results demonstrate a similar CEC of the biochar after $\mathrm{H}_{2} \mathrm{O}_{2}$ modification, i.e. from $2.0( \pm 0.1)$ to $3.0( \pm 0.1) \mathrm{cmol}^{+} \mathrm{kg}^{-1}$, whereas the CEC values were much higher (7-10 times) for BKOH $\left(13.4 \pm 0.1 \mathrm{cmol}^{+} \mathrm{kg}^{-1}\right)$ and $\mathrm{BKOH}^{\text {bat }}\left(20.8 \pm 0.1 \mathrm{cmol}^{+} \mathrm{kg}^{-1}\right)$ (Table 1). Nevertheless, in the literature much higher CEC values are reported for wood and straw derived biochars, ranging from 45.7 to 483.4 $\mathrm{cmol}^{+} \mathrm{kg}^{-1}$ (Ding et al., 2016; Jiang et al., 2014).

The biochar properties reported in Table 1 highlight that the total As content, zeta potential and $\mathrm{S}_{\mathrm{BET}}$ are the key indicators that were significantly affected by the biochar treatment. Due to its lower negative charge and its higher $\mathrm{S}_{\mathrm{BET}}$, $\mathrm{BKOH}$ can potentially sorb more As compared to other biochars. Furthermore, the biochar washing procedure is an important 
parameter to be considered after the chemical treatment, since the biochar properties significantly change between $\mathrm{BKOH}$ and $\mathrm{BKOH}^{\text {bat }}$.

\subsection{As redox state evolution during sorption kinetics by $\mathrm{BKOH}^{\text {bat }}$ and its dissolved solutions}

Fig. 1a shows the As redox state distribution in the solution during adsorption experiments for $\mathrm{As}(\mathrm{III})$ onto $\mathrm{BKOH}^{\text {bat }}$. The results demonstrate that while As was gradually sorbed onto $\mathrm{BKOH}^{\text {bat }}$ (corresponding to the decrease of total As over time), the oxidation of As(III) to $\operatorname{As}(V)$ occurred continuously. To elucidate whether this oxidation was promoted by compounds released from the biochar into the solution or by the biochar itself, a control experiment was performed by replacing the biochar by a solution of released dissolved compounds (RDC) from $\mathrm{BKOH}^{\text {bat }}$. The experimental data and corresponding results is shown in Fig. 1b. From the results, a slight oxidation of As(III) with a final proportion of 9\% $\mathrm{As}(\mathrm{V})$ in the RDC solution was found, compared to $43 \%$ oxidation with the presence of biochar. This demonstrates that the oxidation of $\mathrm{As}(\mathrm{III})$ to $\mathrm{As}(\mathrm{V})$ was mainly induced by the biochar material itself and to a lesser extent by the dissolved compounds being released from the $\mathrm{BKOH}^{\text {bat }}$. At present, there is still a lack of information on the role of biochars and the released dissolved compounds towards the As(III) oxidation. Nevertheless, the findings are supported by Niazi et al. (2018a, 2018b) who found the oxidation of As(III) sorbed onto biochars prepared from Japanese oak wood and perilla leaf. However, Dong et al. (2014) showed the high potential oxidation of As(III) (up to 25\%) induced by the dissolved organic matter from sugar beet tailing and Brazilian pepper derived biochars. 


\subsection{Extraction procedure for As redox state distribution in biochars}

In order to assess the redox state distribution of As sorbed onto biochar by LC-AFS, it was first necessary to validate an extraction procedure that allows a quantitative As recovery without any conversion of As species, especially As(III) being oxidized to As(V).

The importance of adding ascorbic acid in the extraction solution to stabilize As(III) was assessed by applying the extraction procedure to a biochar sample with and without spiking with a known amount of As(III) just before performing the extraction step. In this study, the $\mathrm{BKOH}^{\text {bat }}$ was selected due to its release of dissolved compounds and its ability to oxidize As(III) as previously reported by Wongrod et al. (2018a, 2018b).

Table 2 shows the recoveries of the arsenic species and total As after the extraction using $\mathrm{H}_{3} \mathrm{PO}_{4}$ with or without addition of ascorbic acid onto the $\mathrm{BKOH}^{\text {bat }}$ sample, and with and without As(III) spiking just before the extraction. Results show that all spiked arsenic was recovered by the extraction procedure. The results also highlight that when using only 0.3 $\mathrm{M} \mathrm{H}_{3} \mathrm{PO}_{4}$, a significant amount of spiked As(III) was oxidized. Indeed, the addition of 12.5 $\mu \mathrm{g}$ of As(III) to the biochar before performing the extraction step resulted in an increase of $8.8( \pm 0.7) \mu \mathrm{g}$ and $3.5( \pm 0.3) \mu \mathrm{g}$ for As(III) and As(V), respectively. Thus, $29 \%$ of spiked As(III) was converted into As(V). In contrast, no oxidation of As(III) was observed during extraction with $\mathrm{H}_{3} \mathrm{PO}_{4}$ and ascorbic acid: the difference between the As(III) amount before and after spiking is $12.6( \pm 0.7) \mu \mathrm{g}$, which is in agreement with the amount of As(III) added $(12.5 \mu \mathrm{g})$. Therefore, the addition of ascorbic acid is essential to ensure As(III) stability during the extraction step. The findings are also in agreement with the study of $\mathrm{Xu}$ et al. 
(2015) who reported the efficiency of using both phosphoric and ascorbic acids as extracting agents to quantitatively recover As(III) and As(V) from fly ash.

To estimate the extraction yield of As sorbed onto the biochar after the As(III) sorption experiments, the biochars were recovered and submitted to both acid digestion and extraction procedures (see section 2.4). The corresponding results are presented in Table 3. For BSS and $\mathrm{BH}_{2} \mathrm{O}_{2}$, the amount of total sorbed As was too low to allow an accurate determination after the acid digestion and/or extraction. As a result, no extraction yield was calculated. For $\mathrm{BKOH}^{\text {bat }}$, the total amount of sorbed As was quantitatively recovered by the extraction procedure. In the case of $\mathrm{BKOH}$, most of the sorbed As was recovered but about one fourth could not be extracted under the applied conditions. This difference in the extraction efficiency may result from different sorption mechanisms of As from one biochar type to the other. Nevertheless, the majority of As could be extracted from the biochars and thus the identification of the As species in the extracted solutions gives the main As species sorbed onto the biochars.

\subsection{Determination of $A s(I I I)$ and $A s(V)$ sorbed onto biochars}

Different types of biochars were exposed in the solution containing an initial As(III) amount of $146 \mu \mathrm{g}$. After $24 \mathrm{~h}$ of As(III) sorption, the biochars were recovered and the exposure solutions were analyzed to determine the remaining amount of As and to assess its distribution between $\mathrm{As}(\mathrm{III})$ and $\mathrm{As}(\mathrm{V})$. The biochars were separately submitted to acid digestion for the determination of the total quantity of sorbed As and to the extraction for the assessment of the redox distribution of sorbed As. The amounts of $\mathrm{As}(\mathrm{III}), \mathrm{As}(\mathrm{V})$ and 
total As in the exposure solutions and sorbed onto the biochars (determined after acid digestion and extraction steps) are shown in Table 4.

Results showed that the total As (i.e. As(III) $+\mathrm{As}(\mathrm{V}))$ remaining in the final exposure solutions of $\mathrm{BSS}$ and $\mathrm{BH}_{2} \mathrm{O}_{2}$ were not significantly different from the initial As(III), indicating that no As was sorbed onto these biochars. In contrast, As was removed from the exposure solutions by both $\mathrm{BKOH}$ and $\mathrm{BKOH}^{\text {bat }}$, corresponding to an As sorption efficiency of $67 \%$ and $50 \%$, respectively. These results are in agreement with the sorption yield estimated with the amount of As quantified in the digestate-based biochars (Table 4).

The arsenic redox distribution in the final exposure solution shows almost no As(III) oxidation for both BSS and $\mathrm{BH}_{2} \mathrm{O}_{2}$ as the final amount of As(III) remained the same as the initial As(III) amount (Table 4). For the $\mathrm{KOH}$ treated biochars, the assessment of the redox distribution only concerned the unsorbed As. In the case of $\mathrm{BKOH}$, no significant oxidation of $\mathrm{As}(\mathrm{III})$ was observed, whereas for $\mathrm{BKOH}^{\text {bat }}$ about $28 \%$ of the remaining As was oxidized to $\mathrm{As}(\mathrm{V})$ (Table 4). These findings are in agreement with a previous study from Wongrod et al. (2018b) with a large oxidation of $\mathrm{As}(\mathrm{III})$ in $\mathrm{BKOH}^{\text {bat }}$ and a partial oxidation in $\mathrm{BKOH}$ during As(III) sorption. As previously discussed (Fig. 1a and 1b), the majority of As(III) oxidation was induced by the biochar solid compounds.

Considering $\mathrm{As}(\mathrm{III})$ and $\mathrm{As}(\mathrm{V})$ extracted from the biochars after the sorption experiment, a similar distribution of the As species was found for $\mathrm{BKOH}$ and $\mathrm{BKOH}^{\text {bat }}$ (Table 4). Arsenic was mainly sorbed as As(III) (90-92\%) and only $8-10 \%$ was sorbed as As(V) onto the $\mathrm{KOH}$ biochars. In the case of $\mathrm{BKOH}$, the redox distribution of As sorbed onto the biochar 
is quite similar to the distribution observed in the final exposure solution. However, for $\mathrm{BKOH}^{\text {bat }}$, the evolution of the As species in solution and on the biochar was different: $\operatorname{As}(\mathrm{V})$ represents only $8 \%$ of the sorbed arsenic whereas it corresponds to $28 \%$ of the dissolved $\mathrm{As}(\mathrm{V})$ (Table 4). This suggests that the $\mathrm{As}(\mathrm{III})$ sorption onto the $\mathrm{KOH}$ biochar was favored compared to $\mathrm{As}(\mathrm{V})$ sorption. This finding is consistent with results previously reported by Wongrod et al. (2018b) when comparing As(III) and As(V) sorption onto such biochars. Another possible explanation would be that $\mathrm{As}(\mathrm{V})$ could be reduced into As(III) during the sorption process, as observed by Niazi et al. (2018a, 2018b) who studied the speciation of As onto wood and leaf derived biochars using the solid-phase XANES technique. Depending on the nature and chemical treatment applied to the biochar, it could also contain chemical functions that act as electron donors to facilitate the As reduction (Choppala et al., 2016).

Comparison of the two KOH biochars showed that the adsorption capabilities for As(III) were quite similar for both the $\mathrm{BKOH}\left(410 \mu \mathrm{g} \mathrm{g}^{-1}\right)$ and $\mathrm{BKOH}^{\text {bat }}\left(385 \mu \mathrm{g} \mathrm{g}^{-1}\right)$ at $\mathrm{As}(\mathrm{III})$ concentration ranges of $0-4000 \mu \mathrm{M}$ (or 0-54 $\mu \mathrm{g} \mathrm{L}^{-1}$ ) and the initial solution $\mathrm{pH}$ at 5.0. Nevertheless, a much higher As(III) sorption was observed onto the Japanese oak wood derived biochar $\left(3,890 \mu \mathrm{g} \mathrm{g}^{-1}\right)$ (concentrations of $27-144 \mu \mathrm{g} \mathrm{L}^{-1}$ and at $\mathrm{pH} 7.0 \pm 0.1$ ) (Niazi et al., 2018b). This is probably due to different biochar properties between the SSDbased biochars and the Japanese oak wood biochar. For instance, the specific surface area was substantially lower with the $\mathrm{KOH}$ modified biochars from SSD $\left(3.0-7.9 \mathrm{~m}^{2} \mathrm{~g}^{-1}\right)$ (Table 1) compared to the oak wood biochar $\left(475 \mathrm{~m}^{2} \mathrm{~g}^{-1}\right)$ (Niazi et al., 2018b). 
In the case of $\mathrm{BH}_{2} \mathrm{O}_{2}$, the amount of sorbed As being low, the results of the As redox distribution were less accurate and should thus be taken with caution. The percentage of $\mathrm{As}(\mathrm{V})$ sorbed onto the $\mathrm{H}_{2} \mathrm{O}_{2}$-modified biochar appears to be higher than into solution, highlighting a potential oxidation of As(III) during sorption. This phenomenon was also observed by Niazi et al. (2018a, 2018b), who suggested that redox active species present at the biochar surface such as $\mathrm{NO}_{3}{ }^{-}$or $\mathrm{FeO}(\mathrm{OH})$ could induce $\mathrm{As}(\mathrm{III})$ oxidation. Therefore, the presence of iron (Fe) $\left(65 \mathrm{~g} \mathrm{~kg}^{-1}\right)$ and manganese $(\mathrm{Mn})\left(769 \mathrm{mg} \mathrm{kg}^{-1}\right)$ on the SSD biochar, that could be partially in metal oxide forms (Wongrod et al., 2018a), could promote the redox transformation of $\mathrm{As}(\mathrm{III})$ to $\mathrm{As}(\mathrm{V})$ on metal oxides associated onto the biochars (Vithanage et al., 2017). Such a phenomenon is also reported by several studies (Han et al., 2011; Manning et al., 2002; Wang et al., 2015).

\section{Conclusions}

The extraction using phosphoric and ascorbic acids allowed recovering sorbed arsenic, while preserving As(III) oxidation state. Arsenic redox distribution could thus be assessed in both solid and liquid phases. Arsenic was mainly sorbed onto biochar as As(III) but during sorption, As(III) oxidation may occur over time. This oxidation, mainly induced by biochar solid compounds rather than by soluble compounds released from biochar, can strongly vary depending on the chemical treatment and efficiency of washing procedures applied to biochar after chemical treatment. The $\mathrm{KOH}$ modification efficiently improves the biochar sorption capacity but also promotes As(III) oxidation, especially with an incomplete washing. 


\section{Acknowledgments}

Patrice Fondanèche (Université de Limoges, France) is acknowledged for technical assistance with arsenic analysis. This research work was economically supported by the Marie Sklodowska-Curie European Joint Doctorate in Advanced Biological Waste-toEnergy (ABWET) under the European Union's Horizon 2020 framework [grant agreement $\left.\mathrm{N}^{\circ} 643071\right]$.

\section{Conflict of interest}

The authors declare no conflict of interest.

\section{References}

1. Agrafioti, E., Bouras, G., Kalderis, D., Diamadopoulos, E., 2013. Biochar production by sewage sludge pyrolysis. J. Anal. Appl. Pyrol. 101, 72-78.

2. Ahmad, M., Rajapaksha, A.U., Lim, J.E., Zhang, M., Bolan, N., Mohan, D., Vithanage, M., Lee, S.S., Ok, Y.S., 2014. Biochar as a sorbent for contaminant management in soil and water: A review. Chemosphere 99, 19-23.

3. Aran, D., Maul, A., Masfaraud, J.F., 2008. A spectrophotometric measurement of soil cation exchange capacity based on cobaltihexamine chloride absorbance. C. R. Geosci. 340, 865-871. 
4. Choppala, G., Bolan, N., Kunhikrishnan, A., Bush, R., 2016. Differential effect of biochar upon reduction-induced mobility and bioavailability of arsenate and chromate. Chemosphere 144, 374-381.

5. Ding, Z., Hu, X., Wan, Y., Wang, S., Gao, B., 2016. Removal of lead, copper, cadmium, zinc, and nickel from aqueous solutions by alkali-modified biochar: Batch and column tests. J. Ind. Eng. Chem. 33, 239-245.

6. Dong, X., Ma, L.Q., Gress, J., Harris, W., Li, Y., 2014. Enhanced Cr(VI) reduction and As(III) oxidation in ice phase: Important role of dissolved organic matter from biochar. J. Hazard. Mater. 267, 62-70.

7. Gong, X.J., Li, W.G., Zhang, D.Y., Fan, W.B., Zhang, X.R., 2015. Adsorption of arsenic from micro-polluted water by an innovative coal-based mesoporous activated carbon in the presence of co-existing ions. Int. Biodeterior. Biodegrad. $102,256-264$.

8. Gonzalez-Garcia, P., 2018. Activated carbon from lignocellulosics precursors: A review of the synthesis methods, characterization techniques and applications. Renew. Sustain. Energ. Rev. 82, 1393-1414.

9. Han, X., Li, Y.L., Gu, J.D., 2011. Oxidation of As(III) by $\mathrm{MnO}_{2}$ in the absence and presence of Fe(II) under acidic conditions. Geochim. Cosmochim. Acta 75, 368379.

10. Huang, H., Tang, J., Gao, K., He, R., Zhao, H., Werner, D., 2017. Characterization of $\mathrm{KOH}$ modified biochars from different pyrolysis temperatures and enhanced adsorption of antibiotics. RSC Adv. 7, 14640-14648.

11. Hughes, M.F., Beck, B.D., Chen, Y., Lewis, A.S., Thomas, D.J., 2011. Arsenic 
exposure and toxicology: A historical perspective. Toxicol. Sci. 123, 305-332.

12. Ifthikar, J., Wang, J., Wang, Q., Wang, T., Wang, H., Khan, A., Jawad, A., Sun, T., Jiao, X., Chen, Z., 2017. Highly efficient lead distribution by magnetic sewage sludge biochar: Sorption mechanisms and bench applications. Bioresour. Technol. $238,399-406$.

13. Jadhav, S.V., Bringas, E., Yadav, G.D., Rathod, V.K., Ortiz, I., Marathe, K.V., 2015. Arsenic and fluoride contaminated groundwaters: A review of current technologies for contaminants removal. J. Environ. Manage. 162, 306-325.

14. Jain, C.K., Singh, R.D., 2012. Technological options for the removal of arsenic with special reference to South East Asia. J. Environ. Manage. 107, 1-18.

15. Jiang, T., Xu, R., Gu, T., Jiang, J., 2014. Effect of crop-straw derived biochars on $\mathrm{Pb}(\mathrm{II})$ adsorption in two variable charge soils. J. Integr. Agric. 13, 507-516.

16. Jin, H., Capareda, S., Chang, Z., Gao, J., Xu, Y., Zhang, J., 2014. Biochar pyrolytically produced from municipal solid wastes for aqueous $\mathrm{As}(\mathrm{V})$ removal: Adsorption property and its improvement with $\mathrm{KOH}$ activation. Bioresour. Technol. $169,622-629$.

17. Lin, Y., Munroe, P., Joseph, S., Henderson, R., Ziolkowski, A., 2012. Water extractable organic carbon in untreated and chemical treated biochars. Chemosphere $87,151-157$.

18. Liou, T.H., Wu, S.J., 2009. Characteristics of microporous/mesoporous carbons prepared from rice husk under base- and acid-treated conditions. J. Hazard. Mater. $171,693-703$.

19. Liu, P., Liu, W.J., Jiang, H., Chen, J.J., Li, W.W., Yu, H.Q., 2012. Modification of 
bio-char derived from fast pyrolysis of biomass and its application in removal of tetracycline from aqueous solution. Bioresour. Technol. 121, 235-240.

20. Lu, H., Zhang, W., Yang, Y., Huang, X., Wang, S., Qiu, R., 2012. Relative distribution of $\mathrm{Pb}^{2+}$ sorption mechanisms by sludge-derived biochar. Water Res. 46, $854-862$.

21. Mahmood, T., Saddique, M.T., Naeem, A., Westerho, P., Mustafa, S., 2011. Comparison of different methods for the point of zero charge determination of $\mathrm{NiO}$. Ind. Eng. Chem. Res. 50, 10017-10023.

22. Manning, B.A., Fendorf, S.E., Bostick, B., Suarez, D.L., 2002. Arsenic(III) oxidation and arsenic(V) adsorption reactions on synthetic birnessite. Environ. Sci. Technol. 36, 976-981.

23. Mohan, D., Sarswat, A., Ok, Y.S., Pittman, C.U., 2014. Organic and inorganic contaminants removal from water with biochar, a renewable, low cost and sustainable adsorbent - A critical review. Bioresour. Technol. 160, 191-202.

24. Montperrus, M., Bohari, Y., Bueno, M., Astruc, A., Astruc, M., 2002. Comparison of extraction procedures for arsenic speciation in environmental solid reference materials by high-performance liquid chromatography-hydride generation-atomic fluorescence spectroscopy. Appl. Organomet. Chem. 16, 347-354.

25. Niazi, N.K., Bibi, I., Shahid, M., Ok, Y.S., Burton, E.D., Wang, H., Shaheen, S.M., Rinklebe, J., Lüttge, A., 2018a. Arsenic removal by perilla leaf biochar in aqueous solutions and groundwater: An integrated spectroscopic and microscopic examination. Environ. Pollut. 232, 31-41.

26. Niazi, N.K., Bibi, I., Shahid, M., Ok, Y.S., Shaheen, S.M., Rinklebe, J., Wang, H., 
Murtaza, B., Islam, E., Farrakh Nawaz, M., Lüttge, A., 2018b. Arsenic removal by Japanese oak wood biochar in aqueous solutions and well water: Investigating arsenic fate using integrated spectroscopic and microscopic techniques. Sci. Total Environ. 621, 1642-1651.

27. Novotny, E.H., Maia, C.M.B.D.F., Carvalho, M.T.D.M., Madari, B.E., 2015. Biochar: Pyrogenic carbon for agricultural use - A critical review. Rev. Bras. Cienc. Solo $39,321-344$.

28. Petrovic, J.T., Stojanovic, M.D., Milojkovic, J.V., Petrovic, M.S., Sostaric, T.D., Lausevic, M.D., Mihajlovic, M.L., 2016. Alkali modified hydrochar of grape pomace as a perspective adsorbent of $\mathrm{Pb}^{2+}$ from aqueous solution. J. Environ. Manage. 182, 292-300.

29. Qiu, Y., Zheng, Z., Zhou, Z., Sheng, G.D., 2009. Effectiveness and mechanisms of dye adsorption on a straw-based biochar. Bioresour. Technol. 100, 5348-5351.

30. Regmi, P., Moscoso, J.L.G., Kumar, S., Cao, X., Mao, J., Schafran, G., 2012. Removal of copper and cadmium from aqueous solution using switchgrass biochar produced via hydrothermal carbonization process. J. Environ. Manage. 109, 61-69.

31. Singh, R., Singh, S., Parihar, P., Singh, V.P., Prasad, S.M., 2015. Arsenic contamination, consequences and remediation techniques: A review. Ecotoxicol. Environ. Saf. 112, 247-270.

32. Sizmur, T., Fresno, T., Akgül, G., Frost, H., Moreno-Jiménez, E., 2017. Biochar modification to enhance sorption of inorganics from water. Bioresour. Technol. 246, $34-47$.

33. Thomas, P., Finnie, J.K., Williams, J.G., 1997. Feasibility of identification and 
monitoring of arsenic species in soil and sediment samples by coupled highperformance liquid chromatography - Inductively coupled plasma mass spectrometry. J. Anal. At. Spectrom. 12, 1367-1372.

34. Vithanage, M., Herath, I., Joseph, S., Bundschuh, J., Bolan, N., Ok, Y.S., Kirkham, M.B., Rinklebe, J., 2017. Interaction of arsenic with biochar in soil and water; A critical review. Carbon 113, 219-230.

35. Wan, J., Pressigout, J., Simon, S., Deluchat, V., 2014. Distribution of As trapping along a ZVI/sand bed reactor. Chem. Eng. J. 246, 322-327.

36. Wang, S., Gao, B., Li, Y., Mosa, A., Zimmerman, A.R., Ma, L.Q., Harris, W.G., Migliaccio, K.W., 2015. Manganese oxide-modified biochars: Preparation, characterization, and sorption of arsenate and lead. Bioresour. Technol. 181, 13-17.

37. Wongrod, S., Simon, S., Guibaud, G., Lens, P.N.L., Pechaud, Y., Huguenot, D., van Hullebusch, E.D., 2018a. Lead sorption by biochar produced from digestates: Consequences of chemical modification and washing. J. Environ. Manage. 219, $277-284$.

38. Wongrod, S., Simon, S., van Hullebusch, E.D., Lens, P.N.L., Guibaud, G., 2018 b. Changes of sewage sludge digestate-derived biochar properties after chemical treatments and the influence on $\mathrm{As}(\mathrm{III}$ and V) and Cd(II) sorption. Int. Biodeterior. Biodegrad. 36, 96-102.

39. Wu, W., Li, J., Lan, T., Müller, K., Khan, N., Chen, X., Xu, S., Zheng, L., Chu, Y., Li, J., Yuan, G., Wang, H., 2017. Unraveling sorption of lead in aqueous solutions by chemically modified biochar derived from coconut fiber: A microscopic and spectroscopic investigation. Sci. Total Environ. 576, 766-774. 
40. Xu, Z., Hu, H.Y., Chen, D.K., Cao, J.X., Yao, H., 2015. Determination of inorganic arsenic speciation in municipal solid waste incineration fly ash by high performance liquid chromatography-hydride generation-atomic fluorescence spectroscopy with phosphoric acid as extracting agent. Chinese J. Anal. Chem. 43, 490-494.

41. Xue, Y., Gao, B., Yao, Y., Inyang, M., Zhang, M., Zimmerman, A.R., Ro, K.S., 2012. Hydrogen peroxide modification enhances the ability of biochar (hydrochar) produced from hydrothermal carbonization of peanut hull to remove aqueous heavy metals: Batch and column tests. Chem. Eng. J. 200-202, 673-680.

42. Yuan, H., Lu, T., Huang, H., Zhao, D., Kobayashi, N., Chen, Y., 2015. Influence of pyrolysis temperature on physical and chemical properties of biochar made from sewage sludge. J. Anal. Appl. Pyrolysis 112, 284-289.

43. Zhang, W., Mao, S., Chen, H., Huang, L., Qiu, R., 2013. Pb(II) and Cr(VI) sorption by biochars pyrolyzed from the municipal wastewater sludge under different heating conditions. Bioresour. Technol. 147, 545-552. 


\section{Table and figure legends}

Table 1. pH, electrical conductivity and surface area of the raw and chemically-modified biochars.

Table 2. Arsenic speciation stability using $\mathrm{H}_{3} \mathrm{PO}_{4}$ with or without ascorbic acid $\left(\mathrm{BKOH}^{\text {bat }}\right.$ sample, with and without As(III) spiking just before extraction).

Table 3. Comparison of total amount of sorbed arsenic determined after acid digestion or extraction procedure.

Table 4. Comparison of As speciation and total As in exposure solutions and sorbed onto biochars (initial As(III) amount in exposure solution: $146 \mu \mathrm{g})$.

Figure 1. Arsenic redox distribution in solution during adsorption kinetics for As(III) by $\mathrm{BKOH}^{\text {bat }}$ (a) and for the control with only released dissolved compounds (RDC) from $\mathrm{BKOH}^{\text {bat }}(\mathrm{b})$. 


\section{Tables}

\section{Table 1}

\begin{tabular}{|c|c|c|c|c|c|c|c|}
\hline Biochar & $\begin{array}{l}\text { Total As } \\
\left(\mu \mathrm{g} \mathrm{g}^{-1}\right)\end{array}$ & $\begin{array}{l}\mathrm{pH} \text { in } \\
\text { water }\end{array}$ & $\mathrm{pH} \mathrm{p}_{\mathrm{pzc}}$ & $\begin{array}{l}\text { Zeta potential } \\
\text { at } \mathrm{pH} 5 \\
(\mathrm{mV})\end{array}$ & $\begin{array}{l}\text { Electrical } \\
\text { conductivity } \\
\left(\text { at } 20^{\circ} \mathrm{C} \text { ) }\right. \\
\left(\mu \mathrm{S} \mathrm{cm}^{-1}\right)\end{array}$ & $\begin{array}{l}\mathrm{S}_{\mathrm{BET}}^{\mathrm{a}} \\
\left(\mathrm{m}^{2} \mathrm{~g}^{-1}\right)\end{array}$ & $\begin{array}{l}\mathrm{CEC}^{\mathrm{b}} \\
\left(\mathrm{cmol}^{+} \mathrm{kg}^{-1}\right.\end{array}$ \\
\hline$\overline{B S S}$ & $47 \pm 1$ & $6.4 \pm 0.1$ & 2.7 & -9.8 & $4.0 \pm 0.1$ & $0.4 \pm 0.1$ & $2.0 \pm 0.1$ \\
\hline $\mathrm{BH}_{2} \mathrm{O}_{2}$ & $29 \pm 1$ & $6.5 \pm 0.1$ & 2.9 & -16.5 & $4.1 \pm 0.3$ & $5.7 \pm 0.1$ & $2.9 \pm 0.1$ \\
\hline $\mathrm{BKOH}$ & $13 \pm 1$ & $8.4 \pm 0.1$ & 3.4 & -8.1 & $6.2 \pm 0.5$ & $7.9 \pm 0.1$ & $13.4 \pm 0.1$ \\
\hline $\mathrm{BKOH}^{\text {bat }}$ & $23 \pm 2$ & $10.0 \pm 0.1$ & 2.9 & -17.1 & $324.0 \pm 2.4$ & $3.0 \pm 0.1$ & $20.8 \pm 0.1$ \\
\hline
\end{tabular}

${ }^{\mathrm{a}} \mathrm{S}_{\mathrm{BET}}$ refers to Brunauer-Emmett-Teller surface area of biochar.

${ }^{\mathrm{b}} \mathrm{CEC}$ refers to cation exchange capacity of biochar.

Note: all values reported are mean of triplicate followed by standard deviation, except $\mathrm{pH}_{\mathrm{PZC}}$ and zeta potential. 


\section{Table 2}

\begin{tabular}{llllll}
\hline Extraction method & & \multicolumn{2}{l}{ Extracted arsenic $(\mu \mathrm{g})$} & \multicolumn{2}{l}{ Spiking recovery ${ }^{\mathrm{a}}$ (\%) } \\
\cline { 3 - 5 } & & As(III) & As(V) & As(III) & Total As \\
\hline No ascorbic acid & Before As(III) spiking & $0.3^{\mathrm{b}} \pm 0.1$ & $1.1 \pm 0.1$ & - \\
& After As(III) spiking & $9.1 \pm 0.7$ & $4.6 \pm 0.3$ & 71 & - \\
& $(12.5 \mu \mathrm{g})$ & & & \\
With ascorbic acid & Before As(III) spiking & $0.4^{\mathrm{b}} \pm 0.1$ & $0.8^{\mathrm{b}} \pm 0.1$ & 101 \\
& After As(III) spiking & $13.0 \pm 0.7$ & $0.8^{\mathrm{b}} \pm 0.1$ & 101 & \\
& $(12.5 \mu \mathrm{g})$ & & &
\end{tabular}

${ }^{a}$ Recovery: amount of spiked As(III) recovered by extraction either as As(III) or total arsenic (i.e.

$\operatorname{As}(\mathrm{III})+\mathrm{As}(\mathrm{V}))$.

${ }^{\mathrm{b}}$ Value close to limit of quantification. 


\section{Table 3}

\begin{tabular}{llll}
\hline Biochar & \multicolumn{2}{l}{ Total arsenic $(\mu \mathrm{g})$} & Recovery from extraction (\%) \\
\cline { 2 - 3 } & Extraction & Acid digestion & \\
\hline $\mathrm{BSS}$ & $0.2 \pm 1$ & $1 \pm 1$ & $\mathrm{na}^{\mathrm{a}}$ \\
$\mathrm{BH}_{2} \mathrm{O}_{2}$ & $3 \pm 1$ & $6 \pm 1$ & na \\
$\mathrm{BKOH}$ & $70 \pm 3$ & $93 \pm 3$ & $75 \pm 4$ \\
$\mathrm{BKOH}^{\text {bat }}$ & $63 \pm 4$ & $60 \pm 3$ & $105 \pm 9$ \\
\hline
\end{tabular}

\footnotetext{
${ }^{a}$ na refers to not available due to very low values detected by liquid chromatography coupled to atomic fluorescence spectroscopy (LC-AFS) and/or graphite furnace atomic absorption spectrometry (GF-AAS).
} 


\section{Table 4}

\begin{tabular}{|c|c|c|c|c|c|c|c|c|c|}
\hline \multirow[t]{5}{*}{ Biochar } & \multicolumn{4}{|c|}{ Exposure solution } & \multicolumn{5}{|c|}{ Sorbed As onto biochar } \\
\hline & \multirow{2}{*}{$\begin{array}{l}\text { Initial } \\
\text { As(III) }\end{array}$} & \multicolumn{3}{|l|}{ Final } & \multicolumn{2}{|c|}{ Acid digestion } & \multicolumn{3}{|c|}{ Extraction } \\
\hline & & $\mathrm{As}(\mathrm{III})+$ & $\mathrm{As}(\mathrm{III})$ & $\operatorname{As}(V)$ & Total & Sorption & $\mathrm{As}(\mathrm{III})^{+}$ & $\mathrm{As}(\mathrm{III})$ & $\mathrm{As}(\mathrm{V}$ \\
\hline & $(\mu \mathrm{g})$ & $\mathrm{As}(\mathrm{V})$ & $(\%)$ & $(\%)$ & As & yield $(\%)$ & $\operatorname{As}(\mathrm{V})$ & & $(\%)$ \\
\hline & & $(\mu \mathrm{g})$ & & & $(\mu \mathrm{g})$ & & $(\mu \mathrm{g})$ & & \\
\hline BSS & 146 & $145 \pm 2$ & 99 & 1 & $1 \pm 1$ & $<1$ & $0.2 \pm 1$ & $\mathrm{na}^{\mathrm{a}}$ & na \\
\hline $\mathrm{BH}_{2} \mathrm{O}_{2}$ & 146 & $143 \pm 3$ & 96 & 4 & $6 \pm 1$ & 4 & & 76 & 24 \\
\hline $\mathrm{BKOH}$ & 146 & $48 \pm 3$ & 98 & 2 & $93 \pm 3$ & 64 & $70 \pm 3$ & 90 & 10 \\
\hline $\mathrm{BKOH}^{\text {bat }}$ & 146 & $72 \pm 5$ & 72 & 28 & $60 \pm 3$ & 41 & $63 \pm 4$ & 92 & 8 \\
\hline
\end{tabular}

${ }^{\mathrm{a}}$ na refers to not available due a value close to limit of quantification. 
Figure
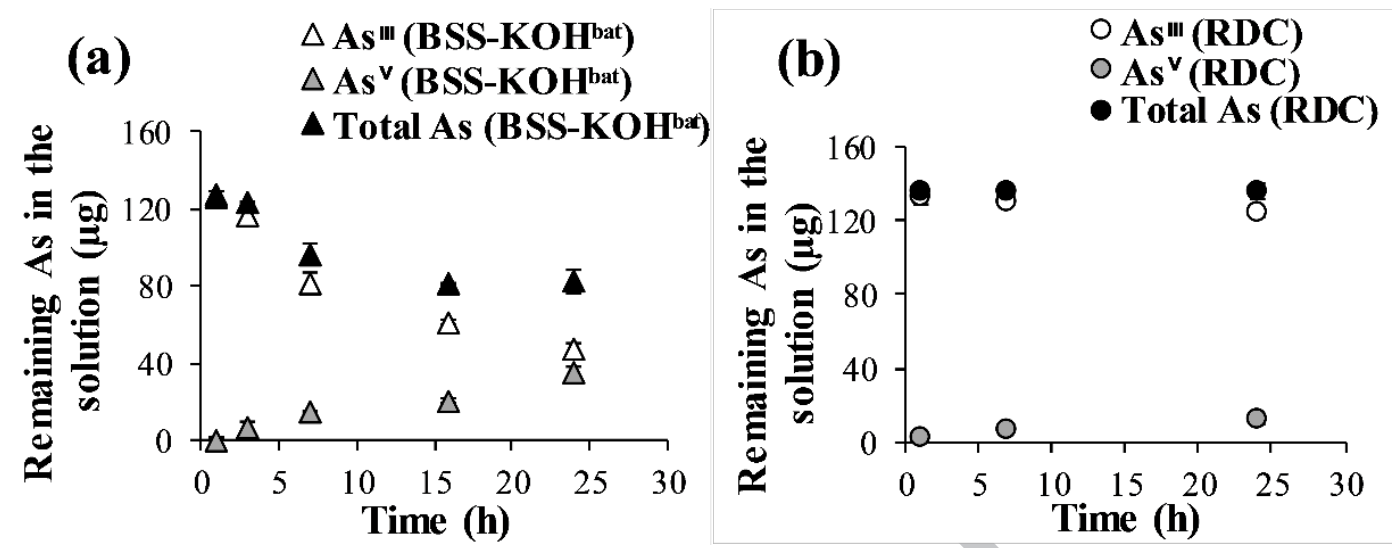

Fig. 1. 